\title{
AVALIAÇÃO DE PROCESSOS NATURAIS DE SALINIZAÇÃO DE ÁGUAS SUBTERRÂNEAS NA PORÇÃO LESTE DA BACIA DO RIO CACHOEIRA, BAHIA
}

Elias Hideo TERAMOTO

CHANG Hung Kiang

\begin{abstract}
RESUMO
Parcela significativa do nordeste brasileiro se notabiliza pela escassez hídrica, que é responsável por implicações socioeconômicas locais negativas. Além do déficit hídrico, esta região é afetada pela salinização de águas subterrâneas, que contribui para a perda de potabilidade da água. Na bacia do rio Cachoeira, Estado da Bahia, situada no limite do semiárido nordestino, as águas subterrâneas possuem concentração de sais dissolvidos naturalmente elevados em razão das altas taxas de evapotranspiração e interação rocha-água. Para a avaliação quantitativa desses processos nas concentrações de sais totais dissolvidos, foram empregadas técnicas estatísticas e simulações geoquímicas. Na análise das Componentes Principais verificou-se que os Componentes Principais $1(\mathrm{CP} 1)$ e $2(\mathrm{CP} 2)$ respondem, respectivamente, por 82,89 e 13,68\% da variância das amostras analisadas. Enquanto o CP1 é majoritariamente atribuído a variações na concentração do íon $\mathrm{HCO}_{3}^{-}$, o CP2 é atribuído a variações na concentração do íon $\mathrm{Cl}^{-}$. Verificou-se três diferentes tendências, que descrevem variações distintas do $\mathrm{CP} 2$ em função daquelas observadas para $\mathrm{CP} 1$, refletindo diferentes proporções na importância da evapotranspiração e interação rocha-água na salinidade. As simulações geoquímicas foram capazes de reproduzir as concentrações das amostras mais salinas, a partir da evaporação e de reações rocha-água. A maior parte das amostras de água subterrânea agrupam-se ao longo da Tendência 3, cujo incremento de sólidos totais dissolvidos é majoritariamente explicado pela interação rocha-água. Em oposição, as amostras de água das Tendências 1 e 2, menos frequentes, possuem sólidos totais dissolvidos majoritariamente provenientes da evaporação da água.
\end{abstract}

Palavras-chave: Salinização; Interação rocha-água; Dissolução de silicatos; Modelagem geoquímica.

\section{ABSTRACT}

ASSESSMENT OF NATURAL GROUNDWATER SALINIZATION PROCESSES IN THE EASTERN PORTION OF THE CACHOEIRA RIVER BASIN, BAHIA. A substantial portion of Northeastern Brazil undergoes water scarcity, which accounts for important negative local socioeconomic impacts. In addition to water deficit, this region is affected by groundwater salinization, which contributes to the loss of water potability. In the Cachoeira River Basin, located on the eastern border of the State of Bahia semiarid region, high concentrations of naturally dissolved salts are found in groundwater, which result from high rates of evapotranspiration and rock-water interaction. For a quantitative assessment of these processes using total dissolved ion concentrations, multivariate statistics and geochemical simulations were used. Principal Component Analysis revealed that Principal Component 1 (PC1) and 2 (PC2) account for 82.89 and $13.68 \%$ of the variance of ion concentrations, respectively. While $\mathrm{PC} 1$ is mostly related to variations in $\mathrm{HCO}_{3}{ }^{-}$concentrations, $\mathrm{PC} 2$ is mostly related to variations in $\mathrm{Cl}^{-}$concentrations. We also verified that hydrochemical changes define three different trends, highlighting $\mathrm{CP} 2$ variations distinct from those observed in $\mathrm{CP} 1$, reflecting different proportions of evapotranspiration and rock-water interaction contributions to 
salinity. Geochemical simulations were able to reproduce ion concentrations in more saline samples from evaporation and rock-water reactions. Most groundwater samples are grouped along Trend 3, whose increase in total dissolved solids is mostly explained by rock-water interactions. Contrarily, the less frequent Trends 1 and 2 are mostly explained by water evaporation.

Keywords: Salinization; Rock-water interaction; Dissolution of silicates; Geochemical modeling.

\section{INTRODUÇÃO}

A qualidade da água subterrânea vem experimentado um forte declínio em várias partes do mundo, em razão dos processos de salinização (e.g. SALAMA et al. 1999, RE \& SACCHI 2017, NOGUEIRA et al. 2019). A salinização de aquíferos é um processo no qual a concentração de sais é incrementada em razão de fatores antrópicos ou naturais (MANCA et al. 2015). Dentre os processos que governam a salinização de águas subterrâneas merecem destaque a evaporação/evapotranspiração, a interação rocha-água, os processos de irrigação e as intrusões salinas promovidas pela exploração excessiva de água subterrânea (SALAMA et al. 1999, KIM et al. 2003, HUMPHRIES et al. 2011, BOUZOURRA et al. 2015, MANCA et al. 2015, WALTER et al. 2017, RE \& SACHI 2017, NOGUEIRA et al. 2019).

A salinização, seja ela proveniente da evaporação ou interação rocha-água, pode fazer com que as águas se tornem impróprias para o uso agrícola, ou ainda promover a elevação das concentrações de espécies químicas nocivas à saúde humana. Dentre as espécies químicas mais nocivas associadas à salinização, destaca-se o $\mathrm{F}^{-}$e o $\mathrm{Cl}^{-}$, particularmente em climas áridos (PAUWELS et al. 2015, NAGARAJU et al. 2016, LI et al. 2016, ADIMALLA \& LI 2019).

Uma possível fonte de sais em aquíferos rasos é a deposição seca, proveniente de aerossóis transportados a partir de correntes atmosféricas (MCDOWEEL et al. 1990, HARA et al. 2004, MANCA et al. 2015). Outra fonte, representada pela interação da água subterrânea com a rocha, pode promover incrementos expressivos na concentração de sais dissolvidos em águas subterrâneas (TIZRO \& VOUDOURIS 2008, YOUSIF \& EL-AASSAR 2018, ADIMALLA\& LI 2019). As regiões áridas estão expostas a déficits extremos de água devido a baixos volumes de chuva e taxas de evapotranspiração relativamente altas. Nessas re- giões, a maior parte da chuva é evapotranspirada, resultando em baixas taxas de recarga das águas subterrâneas e em incremento de sua salinidade (TWEED et al. 2011, BOUZOURRA et al. 2015, KARROUM et al. 2017). Embora a evapotranspiração possa ser considerada o principal processo de salinização em climas áridos, a interação rocha-água pode responder por parcela significativa da salinização (SALAMA et al. 1999, YOUSIF \& ELAASSAR 2018, ADIMALLA \& LI 2019).

A região do semiárido brasileiro abrange uma área de 1.069.565,71 km², o que corresponde a 12,6 $\%$ do território nacional, abrangendo 1.262 munícipio e 26,5 milhões de habitantes (SUDENE 2017). Esta região é caracterizada por valores de precipitações acumuladas anuais abaixo de $800 \mathrm{~mm} / \mathrm{ano}$, índice de aridez de Thornthwaite inferior a 0,50 e déficit hídrico superior a 60\% (SUDENE 2017). Além da escassez de água, o semiárido e regiões próximas são notabilizadas por valores elevados de salinidade das águas subterrâneas que, na maior parte dos casos, não atendem plenamente aos padrões de potabilidade (INSA 2020). As condições climáticas observadas no semiárido propiciam a salinização das águas subterrâneas. Embora a salinização de águas subterrâneas no semiárido do nordeste brasileiro seja muito reportada na literatura (MOREIRA-NORDEMANN 1984, ANDRADE et al. 1999, BOUAZIZ et al. 2011, ALMEIDA \& FRISCHKORN 2015, SILVA et al. 2018), estudos sobre a avaliação quantitativa dos processos que governam este fenômeno são escassos.

Tendo em vista a carência de água em regiões secas, a perda de potabilidade em razão da salinização tem fortes implicações ambientais e socioeconômicas. Em razão dos efeitos adversos da salinização dos recursos hídricos subsuperficiais no semiárido brasileiro, o desenvolvimento de metodologias para avaliar quantitativamente tais processos possuem elevada relevância e podem servir como subsídio para avaliar o risco de salinização a partir da extração de água subterrânea, irriga- 
ção ou mudanças climáticas, prevendo a perda de potabilidade em regiões marcadas pelo déficit hídrico. Diante do contexto apresentado, o presente trabalho visa aprimorar a quantificação dos efeitos dos diferentes mecanismos envolvidos na salinização de aquíferos cristalinos em regiões semiáridas, propondo e aplicando uma abordagem metodológica, que integra análises estatísticas multivariadas e simulações geoquímicas.

\section{CONTEXTUALIZAÇÃO DA ÁREA DE ESTUDO}

A bacia hidrográfica do rio Cachoeira (BHRC), situada na porção leste do estado da Bahia, região nordeste do Brasil (Figura 1), abrange uma área de $4.288,14 \mathrm{~km}^{2}$. A BHRC encontra-se na transição do tipo climático tropical úmido e semiárido, observado, respectivamente, nas regiões leste e oeste da bacia. ENGELBRECHT et al. (2019) apontaram que as taxas de precipitação acumulada anual na BHRC crescem de oeste (mínimo de 785 $\mathrm{mm} / \mathrm{ano})$ para leste, na região litorânea $(1.650 \mathrm{~mm} /$ ano). De acordo com o balanço hídrico apresentado pelos mesmos autores, $85 \%$ da precipitação é evapotranspirada. Em razão das elevadas taxas de evapotranspiração, é observada uma forte salinização das águas subterrâneas e superficiais, reportada em diversos trabalhos (MOREIRA-NORDEMANN 1984, SANTOS et al. 2008, LUCIO et al. 2012, TERAMOTO et al. 2018).

Geologicamente, a BHRC está localizada sobre rochas do Embasamento Cristalino pertencentes ao domínio Itabuna-Salvador-Curaçá, composto pelo Cinturão de Itabuna, ao sul, e SalvadorCuraçá, ao norte (PINHO 2005) (Figura 1). Essas unidades são predominantemente compostas por granulitos tonalíticos e trondhjemíticos, subdivididas em séries toleíticas, cálcio-alcalinas de baixo potássio e shoshoníticas, associadas a bandas me-
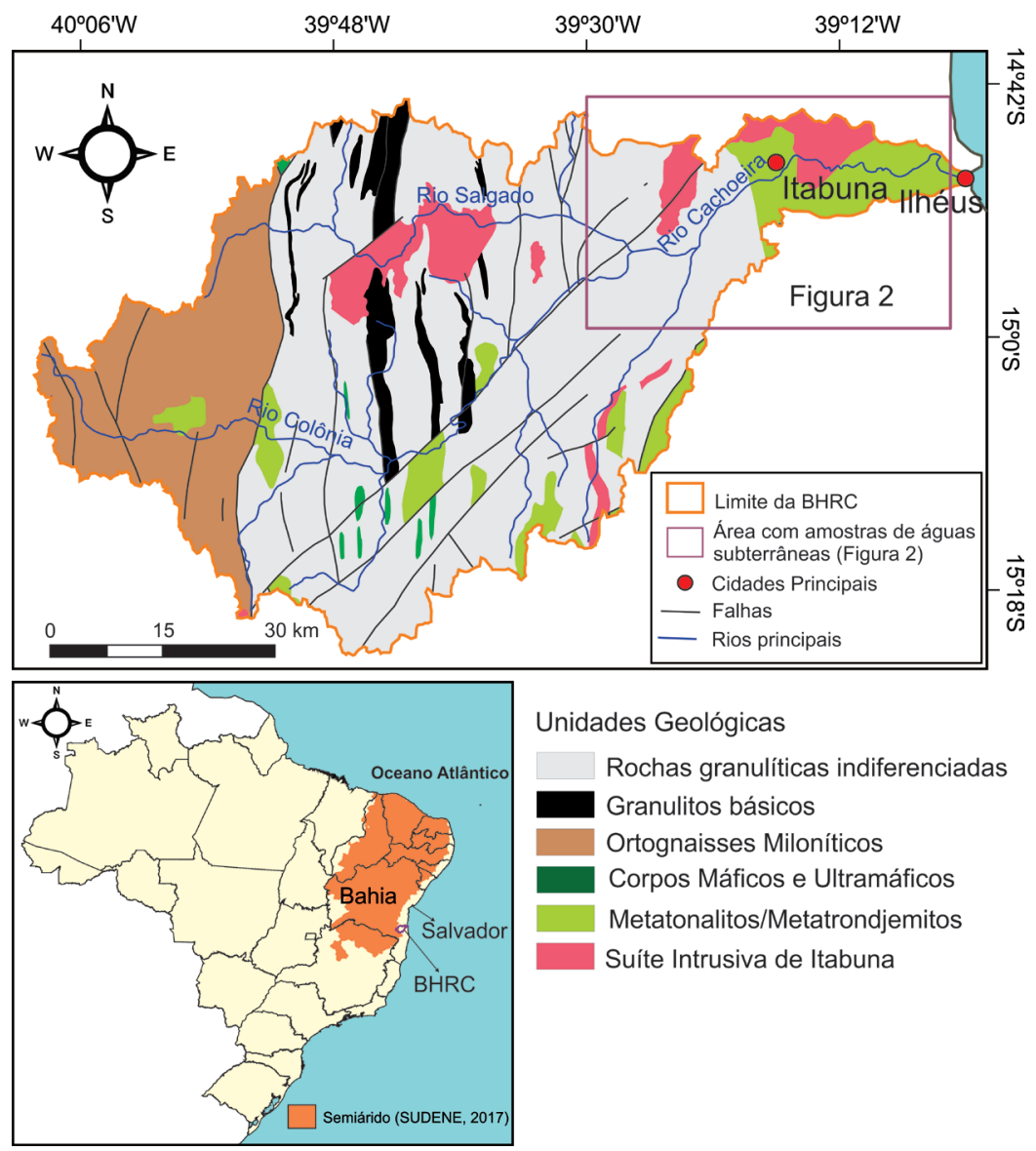

Unidades Geológicas

Rochas granulíticas indiferenciadas

Granulitos básicos

Ortognaisses Miloníticos

Corpos Máficos e Ultramáficos

Metatonalitos/Metatrondjemitos

Suíte Intrusiva de Itabuna

FIGURA 1 - Mapa geológico da Bacia Hidrográfica do Rio Cachoeira (adaptado de PINHO 2005). No mapa abaixo, é ilustrada a localização do Semiárido no território brasileiro (SUDENE 2017). A região onde as amostras de água subterrâneas foram coletadas (Figura 2), é destacada no mapa geológico da bacia. 
tassedimentares e basaltos e gabro-oceânicos e/ou bacias back-arc (BARBOSA \& SABATÉ 2002).

\section{MATERIAS E MÉTODOS}

\subsection{Análises hidroquímicas}

Para fins de aplicação da metodologia proposta no presente trabalho, foram empregados 27 dados hidroquímicos revisados (amostras AS1 a AS27), previamente apresentados por TERAMOTO et al. (2018). A amostragem de água nos poços tubulares em operação foi realizada em torneiras conectadas na boca do poço; no caso de poços do tipo cacimba ou poços tubulares desativados, ela foi realizada com o emprego de um bailer de polipropileno descartável. Os parâmetros físico-químicos $(\mathrm{pH}$, condutividade elétrica e potencial de oxi-redução - ORP) foram determinados in situ empregando a sonda multiparâmetros da marca Yellowsprings $^{\circledR}$ (YSP). Os ânions foram determinados por cromatografia iônica, os cátions por espectrometria de emissão óptica com plasma (ICP-
OS) e a alcalinidade, por intermédio da titulação potenciométrica empregando $\mathrm{HCl}$ como titulante. Ao conjunto amostral previamente apresentado por TERAMOTO et al. (2018), foram acrescentadas três análises químicas fornecidas por empresas particulares (AS28 a AS30). A figura 2 apresenta a localização das amostras avaliadas no presente trabalho; a tabela 1 apresenta o conjunto de análises físico-químicas dessas amostras.

\subsection{Análise estatística dos dados hidroquímicos}

Com o intuito de diferenciar os processos de salinização associados à evapotranspiração e à interação rocha-água, foram realizadas análises estatísticas simples e multivariadas, empregando o aplicativo PAST 3.25 (HAMMER et al. 2009).

\subsubsection{Análise estatística descritiva}

As análises estatísticas univariadas foram efetuadas por meio da construção de diagramas de caixa dos parâmetros físico-químicos $(\mathrm{pH}$, Eh, condutividade elétrica) e sólidos totais dissolvidos.

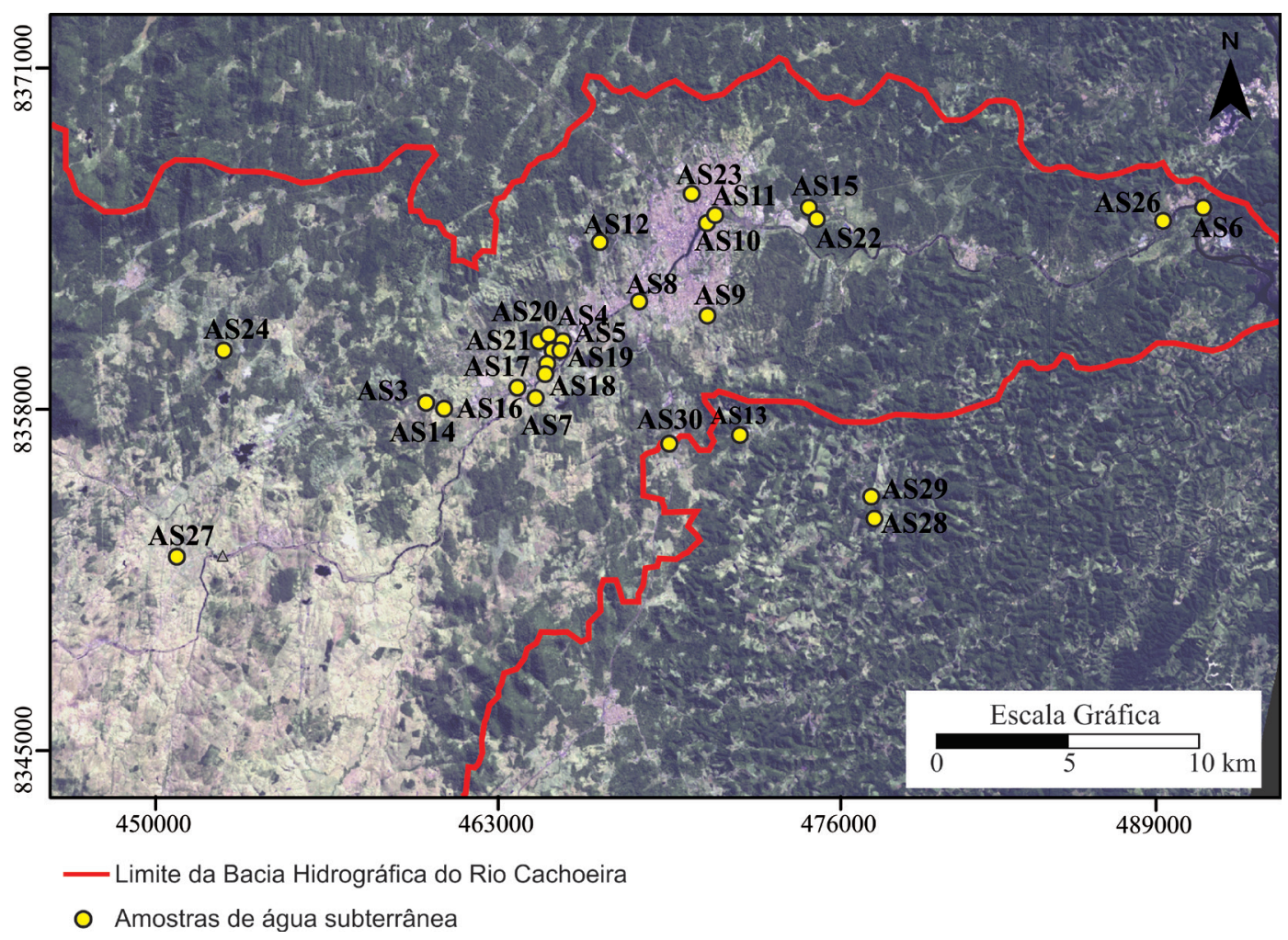

FIGURA 2 - Localização das amostras de água subterrânea, cujas análises foram empregadas no presente trabalho. Vide localização da área no mapa geológico da figura 1. 


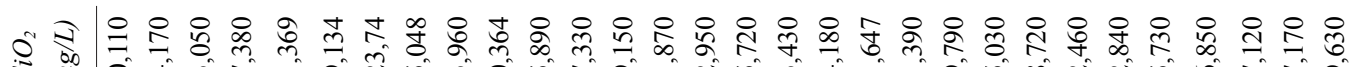

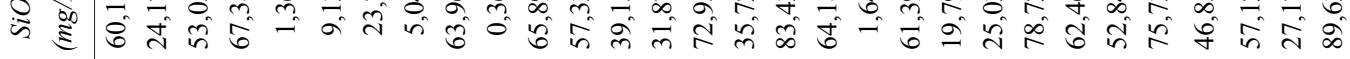
ฟ

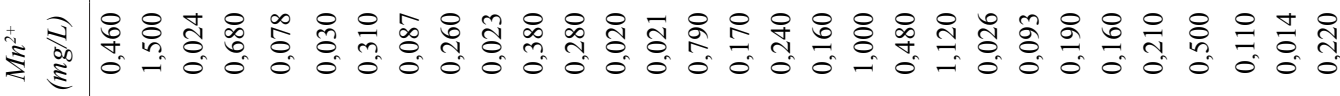

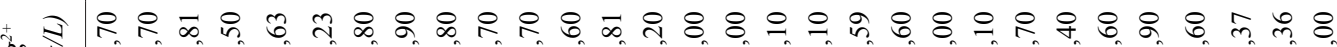

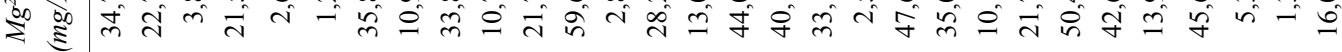

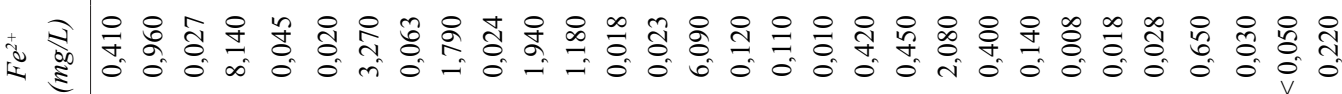

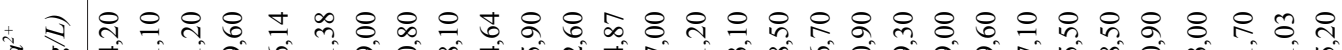
उह हैं

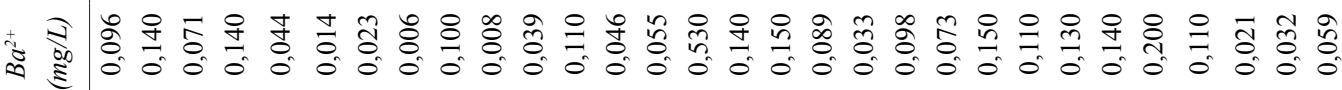

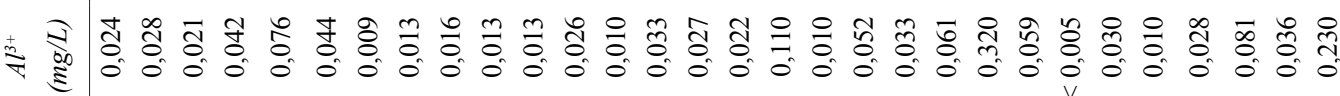
가열

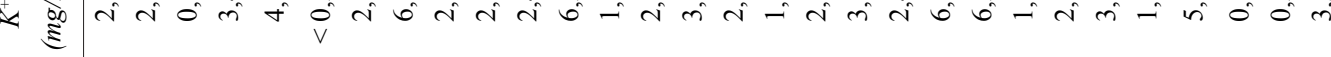

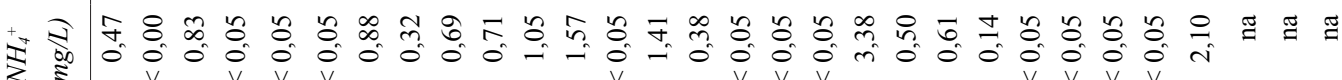

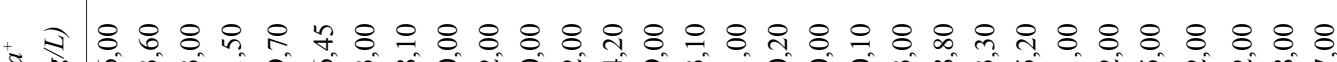

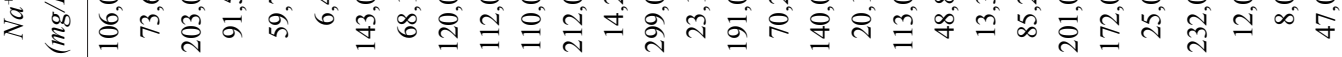

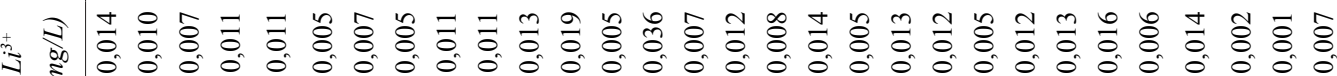
ह $v$ V

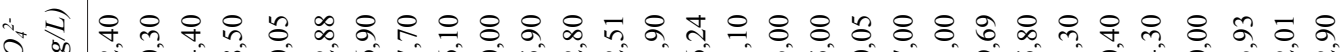
फी

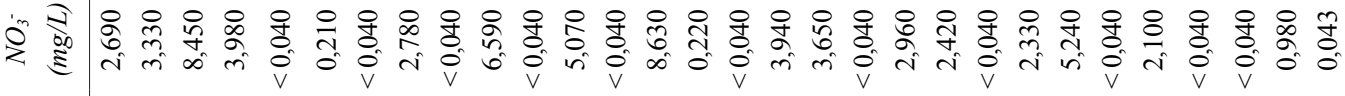
근 8 요 च हैं

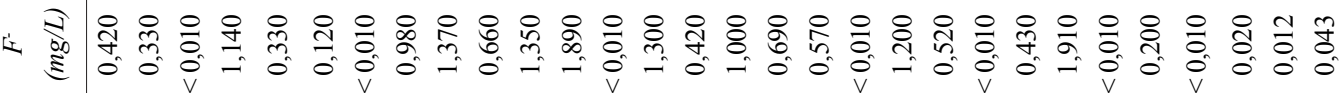

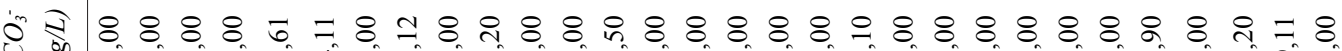

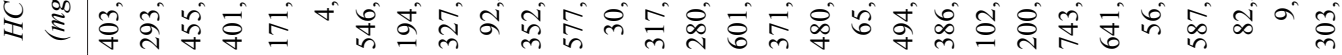

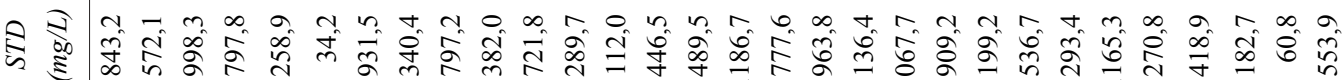

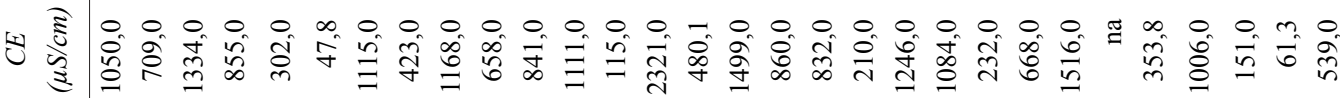

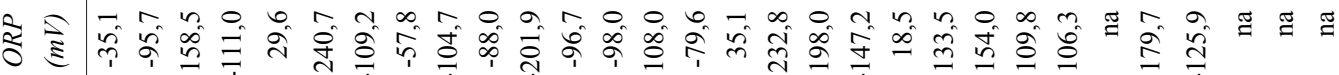

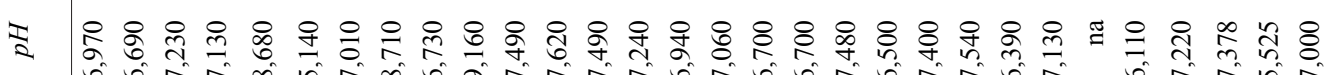

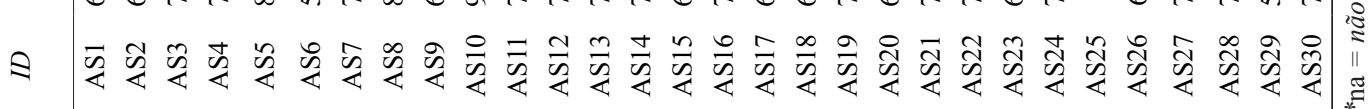




\subsubsection{Análises de Componentes Principais}

Em razão do grande número de espécies químicas identificadas, foi empregada a técnica de Análise de Componentes Principais (ACP) para avaliação da inter-relação entre as diversas amostras de água. A ACP constitui um procedimento estatístico multivariado que utiliza uma transformação ortogonal para converter um conjunto de observações de variáveis, tal como espécies químicas dissolvidas na água, em um conjunto de valores de variáveis linearmente não correlacionadas, conhecidas como componentes principais (TABACHNICK et al. 2007). O número de componentes principais é sempre menor ou igual ao número de variáveis originais. A distribuição do conjunto amostral avaliado na ACP permite a identificação de agrupamentos, tendências e dados anômalos (outliers). No presente trabalho, a ACP foi empregada para diagnosticar diferentes tendências ao longo das componentes que explicam maior variabilidade das amostras. Supõe-se que essas tendências representem proporções variáveis de evapotranspiração e interação rocha-fluido e que as amostras situadas nos extremos dessas tendências correspondam àquelas nas quais tais processos atuaram mais intensamente.

A potencialidade do ACP para identificar processos envolvidos na composição química de águas subterrâneas foi demonstrada por diversos trabalhos (THYNE et al. 2004, LOURENÇO et al. 2010, UMARANI et al. 2019).

\subsubsection{Análises de regressão múltipla}

Enquanto a regressão linear simples avalia a relação causal de dependência entre uma variável independente $(\mathrm{X})$ e uma variável dependente $(\mathrm{Y})$, a regressão múltipla considera simultaneamente a influência de múltiplas variáveis independentes $\left(\mathrm{X}_{1}, \mathrm{X}_{2}, \mathrm{X}_{3} \ldots \mathrm{X}_{\mathrm{n}}\right)$ para explicar as variações de uma variável dependente $\mathrm{Y}$ (Eq. 1).

$$
Y=\beta_{1} X_{1}+\beta_{2} X_{2}+\beta_{3} X_{3} \ldots \beta_{n} X_{n}+\varepsilon
$$

Onde $\beta_{1}, \beta_{2}, \beta_{3} \ldots \beta_{n}$ são os coeficientes obtidos a partir da regressão linear múltipla e $\varepsilon$ o erro da estimativa.

Nas águas subterrâneas um mesmo íon pode ser derivado de fontes distintas. Para exemplificar, o $\mathrm{Na}^{+}$pode ser proveniente tanto da dissolução do $\mathrm{NaCl}$ como da hidrólise de albita $\left(\mathrm{NaAlSi}_{3} \mathrm{O}_{8}\right)$, podendo ser correlacionado com os ânions $\mathrm{Cl}^{-}$e $\mathrm{HCO}_{3}{ }^{-}$ . Neste caso específico, uma regressão linear simples entre as concentrações de $\mathrm{Na}^{+}$e $\mathrm{Cl}^{-}$permite a elaboração de um modelo com um determinado valor de coeficiente de determinação $\left(\mathrm{R}^{2}\right)$. Ao realizar uma análise de regressão múltipla, empregando-se o $\mathrm{Na}^{+}$como variável dependente e $\mathrm{Cl}^{-}$e $\mathrm{HCO}_{3}{ }^{-}$como variáveis independentes, o modelo linear produzido fornece um erro menor e um valor de coeficiente de determinação múltiplo ( $\mathrm{R}^{2}$ ajustado) superior ao $\mathrm{R}^{2}$ obtido na regressão linear simples. A diferença entre o $R^{2}$ ajustado e o $\mathrm{R}^{2}$ simples representa a proporção em que o íon $\mathrm{Na}^{+}$é estatisticamente explicado pelas variações do íon $\mathrm{HCO}_{3}$. A partir deste procedimento é possível determinar a contribuição relativa, do ponto de vista estatístico, de cada parâmetro independente em relação à variável dependente.

Considerando a ausência de rochas carbonáticas na área de estudo, o $\mathrm{HCO}_{3}{ }^{-}$é diagnóstico da interação rocha-água. Por esta razão, foi realizada a análise de regressão linear múltipla utilizando o $\mathrm{HCO}_{3}{ }^{-}$como variável dependente e os diversos cátions dissolvidos na água, de forma a avaliar os possíveis minerais que reagiram com a água. Uma vez que o íon $\mathrm{Na}^{+}$pode ser proveniente tanto da dissolução de silicatos como da evaporação de água contendo aerossol marinho, foi realizada a análise de regressão múltipla utilizando $\mathrm{o} \mathrm{Na}^{+}$ como variável dependente e o $\mathrm{Cl}^{-}$e o $\mathrm{HCO}_{3}^{-}$como independentes.

\subsection{Modelo conceitual para salinização}

Para conduzir as simulações geoquímicas, foi elaborado um modelo conceitual com um conjunto de premissas que descrevem a salinização da água subterrânea na BHRC, como resultado da interação rocha-água e evapotranspiração. Um modelo conceitual para explicar o incremento de salinidade na água subterrânea na área de estudo já havia sido descrito por TERAMOTO et al. (2019a) a partir de dados hidroquímicos (TERAMOTO et al. 2018). Entretanto, ele assumia que toda a água subterrânea na área de estudo fosse submetida a uma mesma intensidade de evaporação e interação rocha-água e as diferenças na tipologia hidroquímica seriam decorrentes de variações litológicas dos aquíferos locais. As simulações identificaram rotas de reação com base apenas na transição de tipologias hidroquímicas, não considerando o incremento de salinidade. No modelo conceitual apresentado no presente trabalho, é adotada a premissa de que a água subterrânea local é submetida a proporções variadas de evaporação e interação rocha-água e as variações nas concentrações de sólidos totais dissolvidos (STD) são consideradas como referência para identificar as diferentes rotas de reação. 
Por intermédio da Análise de Componentes Principais, foram identificadas tendências que representam diferentes rotas de reação, relacionadas à interação rocha-água ou evaporação. As análises de regressão linear múltipla permitiram avaliar os cátions mais fortemente correlacionadas com o $\mathrm{HCO}_{3}$ , oferecendo evidências dos minerais que participam das reações de interação rocha-água. Nas seções seguintes são apresentados os dois mecanismos propostos para incremento de salinidade na BHR.

\subsubsection{Efeito da interação rocha-água}

Embora a composição da água subterrânea seja reflexo direto da composição da rocha, como afirmam diversos autores (p. ex., ELANGO \& KANNAN 2007), o trabalho de TERAMOTO et al. (2019b) sugere que a composição da água é francamente dependente da composição da fração mineralógica mais reativa (particularmente os minerais máficos). A partir da simulação geoquímica de 38 amostras de água envazadas de aquíferos cristalinos, TERAMOTO et al. (2019b) identificaram que, a despeito da diversidade geológica dos locais, a água subterrânea de aquíferos em terrenos granítico-gnáissicos pode ser perfeitamente explicada pela hidrólise de feldspatos potássicos (Equação 2), plagioclásios (Equações 3 e 4) e anfibólios (Equação 5). As reações de hidrólise dos membros finais da série dos plagioclásios - anortita e albita - são apresentadas, respectivamente, nas equações 3 e 4 . De acordo com PINHO et al. (2011), os granulitos tonalíticos e trondhjemíticos, rochas que predominam na área de estudo, foram produzidos por cristalização fracionada, com assembleia mineralógica onde predominam a hornblenda e plagioclásios, com quantidades subordinadas de magnetita, apatita, alanita e zircão. Por esta razão, as reações 2 a 5 representam satisfatoriamente a interação da água com as rochas tonalíticas e trondhjemíticas.

$$
\begin{aligned}
& 2 \mathrm{KAlSi}_{3} \mathrm{O}_{8}+2 \mathrm{CO}_{2}+11 \mathrm{H}_{2} \mathrm{O} \rightarrow \\
& \mathrm{Al}_{2} \mathrm{Si}_{2} \mathrm{O}_{5}(\mathrm{OH})_{4}+2 \mathrm{~K}^{+}+2 \mathrm{HCO}_{3}^{-}+4 \mathrm{Si}(\mathrm{OH})_{4} \text { (Eq. 2) } \\
& \mathrm{CaAlSi}_{3} \mathrm{O}_{8}+2 \mathrm{CO}_{2}+3 \mathrm{H}_{2} \mathrm{O} \rightarrow \\
& \mathrm{Al}_{2} \mathrm{Si}_{2} \mathrm{O}_{5}(\mathrm{OH})_{4}+\mathrm{Ca}^{2+}+2 \mathrm{HCO}_{3}^{-}+4 \mathrm{Si}(\mathrm{OH})_{4} \quad \text { (Eq. 3) } \\
& 2 \mathrm{NaAlSi}_{3} \mathrm{O}_{8}+2 \mathrm{CO}_{2}+11 \mathrm{H}_{2} \mathrm{O} \rightarrow \\
& \mathrm{Al}_{2} \mathrm{Si}_{2} \mathrm{O}_{5}(\mathrm{OH})_{4}+2 \mathrm{Na}^{+}+2 \mathrm{HCO}_{3}^{-}+4 \mathrm{Si}(\mathrm{OH})_{4} \text { (Eq. 4) } \\
& \mathrm{Ca}_{2} \mathrm{Mg}_{2} \mathrm{Si}_{8}(\mathrm{OH})_{2}+14 \mathrm{CO}_{2}+22 \mathrm{H}_{2} \mathrm{O} \rightarrow \\
& 2 \mathrm{Ca}^{2+}+5 \mathrm{Mg}^{2+}+14 \mathrm{HCO}_{3}^{-}+8 \mathrm{Si}(\mathrm{OH})_{4} \text { (Eq. 5) }
\end{aligned}
$$

Como apresentado nas equações 2 a 5 , o $\mathrm{HCO}_{3}{ }^{-}$é produzido pela hidrólise de silicatos, principal reação relacionada à interação rocha-água em rochas cristalinas, como em terrenos graníticos/ gnáissicos, quando o sistema é tamponado por valores elevados de pressão parcial de $\mathrm{CO}_{2}$ (BANKS \& FRENGSTAD 2006, ELANGO \& KANNAN 2007, TERAMOTO et al. 2019b). Entretanto, cabe ressaltar que a alcalinidade pode ser empregada como parâmetro para estimar o grau de interação com as rochas graníticas/gnáissicas apenas quando o $\mathrm{pH}$ é mantido abaixo de 8 e sob tamponamento promovido por elevados valores de pressão parcial do $\mathrm{CO}_{2}$.

\subsubsection{Efeitos da evapotranspiração}

Em razão da proximidade da área de estudo com a região costeira, é esperado que aerossóis marinhos trazidos pelas correntes de ar se assentem em quantidades significativas sobre as folhas da vegetação e na superfície do terreno, na forma de deposição seca. ARAÚJO et al. (2015) verificaram que a quantidade de aerossóis marinhos depositados em diferentes pontos amostrais do Rio Cachoeira é bastante expressiva, respondendo por fluxos significativos dos íons $\mathrm{Na}^{+}, \mathrm{Mg}^{2+}$ e $\mathrm{Cl}^{-}$na área de estudo. Durante o período chuvoso, os aerossóis depositados são dissolvidos pela água meteórica e transportados para o solo, onde os sais dissolvidos se infiltram. Durante os períodos de estiagem, os sais são acumulados na zona não saturada rasa ascendem por capilaridade em razão da evapotranspiração, o que promove o incremento na concentração de sais. ENGELBRECHT et al. (2019), a partir dos cálculos de balanço hídrico da bacia do rio Cachoeira, estimaram que a evapotranspiração corresponde a $85 \%$ da precipitação acumulada anual. Por esta razão, é esperado que a concentração de sais dissolvidos seja fortemente incrementada mediante esse processo.

É preciso notar que os íons $\mathrm{Na}^{+}$e $\mathrm{Mg}^{2+}$ atribuídos à deposição e dissolução de aerossóis marinhos também podem ser provenientes da dissolução de silicatos. Em contrapartida, estes íons podem ser removidos da água a partir da incorporação destes na estrutura cristalina de argilominerais ou ainda serem adsorvidos em reações de troca catiônica. Em razão das condições redutoras observadas em inúmeras amostras de água subterrânea (Tabela 1), é esperado que parcela significativa do $\mathrm{SO}_{4}{ }^{2-}$ trazido pelos aerossóis seja reduzido para $\mathrm{H}_{2} \mathrm{~S}^{-}$. $\mathrm{O} \mathrm{Cl}^{-}$representa a única espécie conservativa, que não é liberado pela hidrólise de silicatos ou retirado da solução na precipitação de argilominerais, podendo assim representar um importan- 
te indicador da salinização associada ao processo de evapotranspiração.

\subsection{Simulação geoquímica}

Com o emprego do modelo conceitual proposto, foram realizadas simulações geoquímicas numéricas empregando o componente React do aplicativo The Geochemist's Workbench ${ }^{\circledR} 10$ (BETHKE \& YEAKEL 2014) para avaliar a importância dos processos de interação rocha-água e de evapotranspiração da água subterrânea no incremento de salinidade. As simulações visaram reproduzir as modificações na composição química da água, à medida que a interação da água com a rocha e a evaporação progridem. Para simular a evaporação, o íon $\mathrm{Cl}^{-}$foi adotado como referência para calcular a quantidade de água a ser subtraída da solução. A massa dos minerais que interagem com a água foi otimizada por tentativa e erro. A calibração procedeu-se avaliando se as soluções geradas pela simulação são compatíveis com as amostras que representam os membros extremos de cada tendência, identificadas na Análise de Componentes Principais.
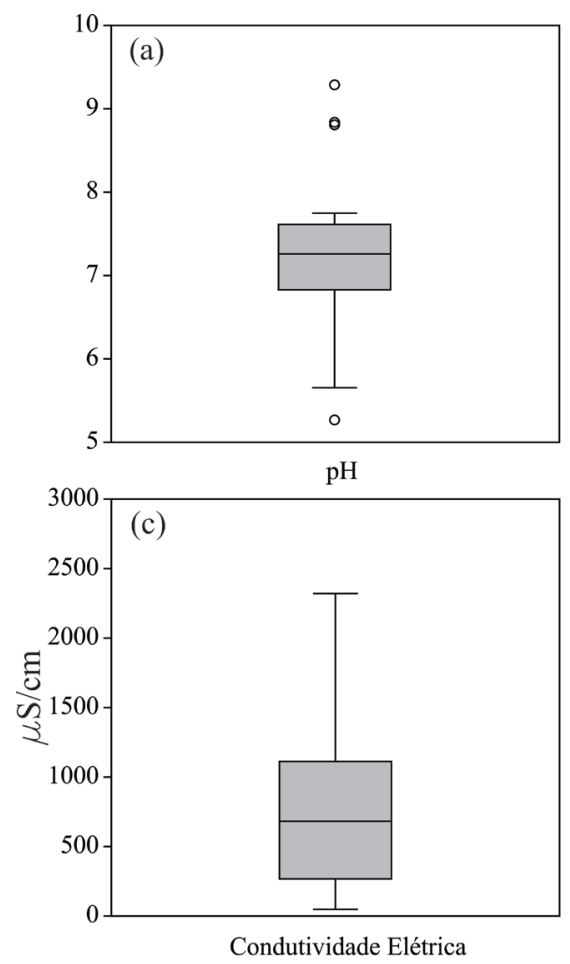

\section{RESULTADOS}

4.1 Análise exploratória dos parâmetros físico-químicos

Para a análise exploratória dos parâmetros $\mathrm{pH}$, potencial de oxi-redução (ORP), condutividade elétrica (CE) e sólidos totais dissolvidos (STD), realizou-se uma análise estatística para determinação de seus intervalos de variação nas amostras de água estudadas. A figura 3 apresenta os diagramas de caixa desses parâmetros. Verifica-se que os parâmetros ORP, CE e STD apresentam uma distribuição lognormal com leve a pronunciada assimetria positiva. $\mathrm{O} \mathrm{pH}$, por outro lado, apresenta uma distribuição lognormal com assimetria negativa, sendo notória a presença de outliers nos valores de $\mathrm{pH}$. A despeito das elevadas concentrações de $\mathrm{HCO}_{3}^{-}$, o pH encontra-se, na maior parte das amostras, abaixo de 7,5, sugerindo o equilíbrio com elevados valores de pressão parcial de $\mathrm{CO}_{2}$. Nota-se que parcela significativa das amostras possuem valores de ORP negativos, provavelmente associados à degradação da matéria orgânica.
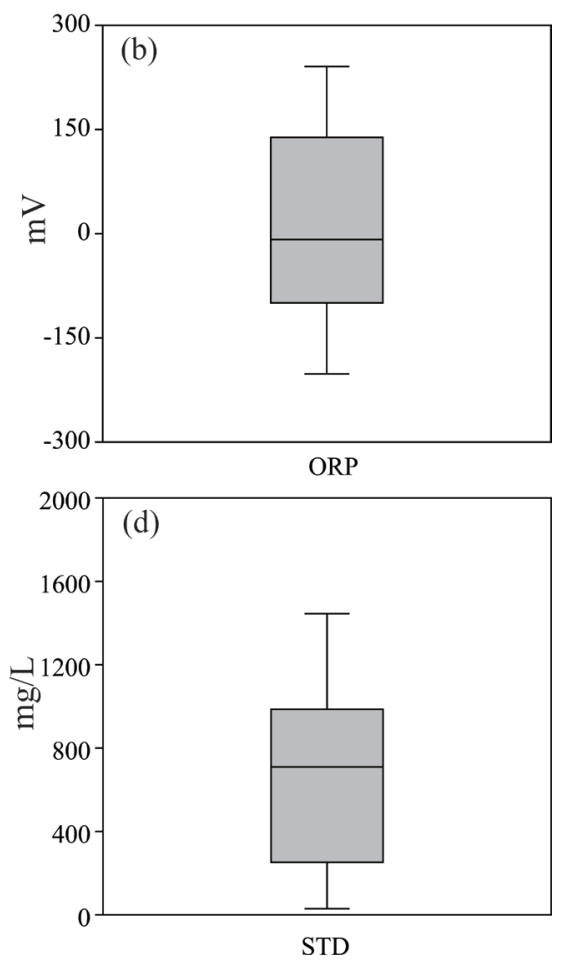

FIGURA 3 - Diagramas de caixa para pH, potencial redox, condutividade elétrica e STD das amostras de água avaliadas. Os limites superior e inferior das linhas representam, respectivamente, os valores máximo e mínimo. Os limites superior e inferior das caixas representam, respectivamente, o terceiro e o primeiro quartil. A linha no interior da caixa representa a mediana. 
O STD, parâmetro que mensura a quantidade de sais dissolvidos na água, é o indicador mais importante para avaliação da salinidade, estando intrinsicamente relacionada com a condutividade elétrica (CE). A partir de regressões não-lineares (Figura 4) foi obtido um modelo empírico que relaciona o STD e a condutividade elétrica na área de estudo, a partir de uma equação exponencial (Equação 6).

$$
S T D=0,505 \cdot C E^{1,071}
$$

A figura 5 apresenta o Diagrama de Piper com a distribuição das amostras de água subterrânea, água superficial e meteórica e a distinção dos valores de STD mensurados. Nota-se que as amostras com elevados valores de STD $(>500 \mathrm{mg} / \mathrm{L})$ pertencem a tipologias hidroquímicas distintas ou bicarbonatadas sódica-magnesianas e cálcica-magnesianas.

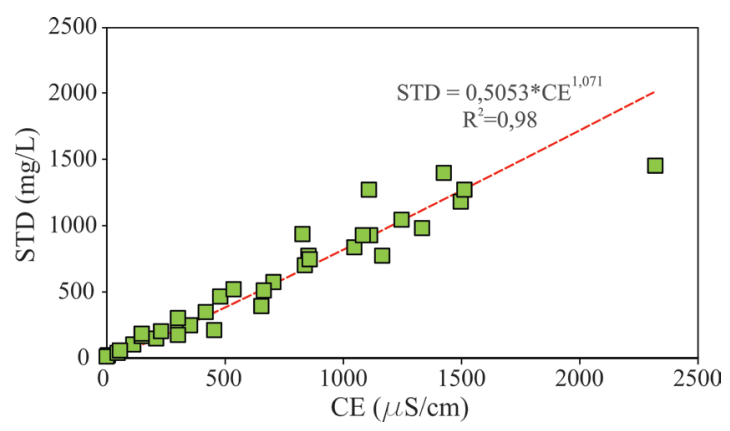

FIGURA 4 - Gráfico de dispersão entre STD e CE das amostras de água avaliadas.

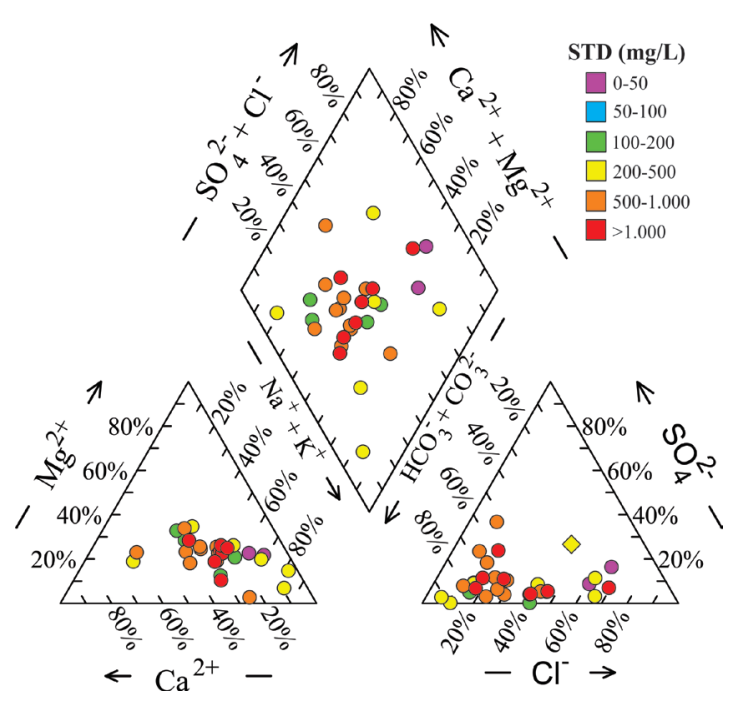

FIGURA 5 - Diagrama de Piper para as amostras compiladas no presente trabalho. As amostras foram classificadas em seis grupos distintos, com base nos valores de STD.
4.2 Identificando tendências a partir da Análise de Componentes Principais

Para identificar tendências de salinização, foi empregado o método de Análise de Componentes Principais utilizando apenas as concentrações dos cátions e ânions maiores. O Componente 1 (CP1) e o Componente 2 (CP2) respondem, respectivamente, por $82,89 \%$ e $13,68 \%$ da variabilidade das amostras analisadas. Tendo em vista que juntas, respondem por $96,57 \%$ da variabilidade das amostras analisadas, o presente trabalho restringiu-se apenas à análise destes dois componentes. A tabela 2 apresenta os coeficientes de ponderação (loading) para definição das Componentes Principais 1 e 2.

TABELA 2 - Coeficientes para definição das Componentes Principais 1 e 2.

\begin{tabular}{ccc}
\hline \multirow{2}{*}{ Parâmetro } & \multicolumn{2}{c}{ Coeficiente de ponderação } \\
& $C P 1$ & $C P 2$ \\
\hline $\mathrm{HCO}_{3}{ }^{-}$ & 0,894 & $-0,378$ \\
$\mathrm{~F}^{-}$ & 0,001 & 0,001 \\
$\mathrm{Cl}-$ & 0,278 & 0,855 \\
$\mathrm{NO}_{3}-$ & 0,004 & 0,011 \\
$\mathrm{SO}_{4}^{2-}$ & 0,109 & $-0,077$ \\
$\mathrm{Li}^{3+}$ & $2,2 \times 10^{-5}$ & $3,6 \times 10^{-5}$ \\
$\mathrm{Na}^{+}$ & 0,292 & 0,337 \\
$\mathrm{~K}^{+}$ & 0,002 & $-0,002$ \\
$\mathrm{Ba}^{2+}$ & $5,8 \times 10^{-5}$ & $-1,9 \times 10^{-4}$ \\
$\mathrm{Ca}^{2+}$ & 0,146 & 0,078 \\
$\mathrm{Fe}^{2+}$ & 0,001 & $-0,003$ \\
$\mathrm{Mg}^{2+}$ & 0,065 & $-0,015$ \\
$\mathrm{Mn}^{2+}$ & $1,5 \times 10^{-4}$ & $-0,001$ \\
$\mathrm{Sr}^{2+}$ & 0,001 & 0,004 \\
\hline
\end{tabular}

4.2.1 CP1: Efeito da interação rocha-água

Na tabela 2 observa-se que os valores de coeficiente de ponderação são elevados para o íon $\mathrm{HCO}_{3}^{-}$, o ânion mais abundante nas amostras avaliadas, enquanto os íons $\mathrm{Cl}^{-}, \mathrm{Na}^{+}$e $\mathrm{Ca}^{2+}$ têm valores mais modestos. Por esta razão, os valores de $\mathrm{CP} 1$ aumentam à medida que as concentrações de $\mathrm{HCO}_{3}{ }^{-}$são incrementadas. Considerando o contexto geológico local, representado apenas por rochas cristalinas e ausência de rochas carbonáticas, o aumento das concentrações de $\mathrm{HCO}_{3}{ }^{-}$está diretamente associado à hidrólise de silicatos, descrito nas equações 2 a 5. Desse modo, é possível as- 
sociar os incrementos dos valores ao longo do eixo da CP1, que descrevem a evolução da interação da água com a rocha.

\subsubsection{CP2: Efeito da evaporação}

Como exposto na tabela 2, os maiores coeficientes de ponderação para o CP2 são atribuíveis aos íons $\mathrm{Cl}^{-}$e, em menor proporção, ao íon $\mathrm{Na}^{+}$. Destaca-se que o íon $\mathrm{HCO}_{3}{ }^{-}$tem um valor de coeficiente de ponderação negativo. Deste modo, o CP2 será incrementado concomitante com as concentrações de $\mathrm{Cl}^{-}$ou $\mathrm{Na}^{+}$, ou quando as concentrações de $\mathrm{HCO}_{3}^{-}$forem reduzidas. Uma vez que $\mathrm{o}^{-} \mathrm{Cl}^{-}$não é liberado pela interação rocha-água e, sim, proveniente da deposição seca de aerossóis marinhos, é possível associar o incremento da CP2 com a intensidade na evapotranspiração da água.

\subsubsection{Separação de tendências}

A figura 6 ilustra o diagrama de ACP, mostrando que as amostras de água subterrânea apresentam fortes variações tanto em relação ao CP1 quanto ao $\mathrm{CP} 2$, refletindo aumento na salinidade, associadas à interação rocha-água e evaporação. Nota-se que as amostras se organizam em três conjuntos distintos, nos quais o crescimento dos valores do CP1 é acompanhado pelo aumento ou decremento do CP2. A estes três conjuntos se ajustam tendências bem definidas (Tendências 1, 2 e 3), que representam três rotas de transformação distintas, nas quais a interação rocha-água e a evaporação possuem contribuições distintas. Nas Tendências 1,2 e 3, os membros extremos são representados pelas amostras AS14, AS27 e AS24.

\subsection{Análise de regressão linear múltipla}

Para identificar a afinidade entre os principais cátions e ânions que contribuem para a salinidade das amostras de água subterrânea, foi elaborada uma matriz de correlação entre essas variáveis (Tabela 3 ).

A matriz de correlação mostra que o bicarbonato, principal ânion nas amostras de água avaliadas e associado à interação rocha-água, correlaciona-se fortemente com $\mathrm{Mg}^{2+}, \mathrm{Ca}^{2+} \mathrm{e} \mathrm{Na}^{+}$. Para melhor investigar a relação entre o bicarbonato e esses cátions, foram elaborados gráficos de dispersão ilustrados na figura 7. A maior afinidade entre o $\mathrm{Mg}^{2+}$ e o $\mathrm{HCO}_{3}{ }^{-} \mathrm{e} \mathrm{Ca}^{2+}$ indica que estas espécies podem ser provenientes da dissolução de anfibólios, que representam uma proporção significativa dos granulitos tonalíticos e trondhjemíticos que predominam na área de estudo. As análises de regressão linear múltipla relevaram que $\mathrm{o} \mathrm{Mg}^{2+}$ responde por $75 \%\left(\mathrm{R}^{2}\right.$ ajustado de 0,75$)$ das variações dos valores de alcalinidade, enquanto o $\mathrm{Na}^{+}$, por $5,9 \%$ (Equação 7). Nota-se que o acréscimo de $\mathrm{Ca}^{2+}$ à

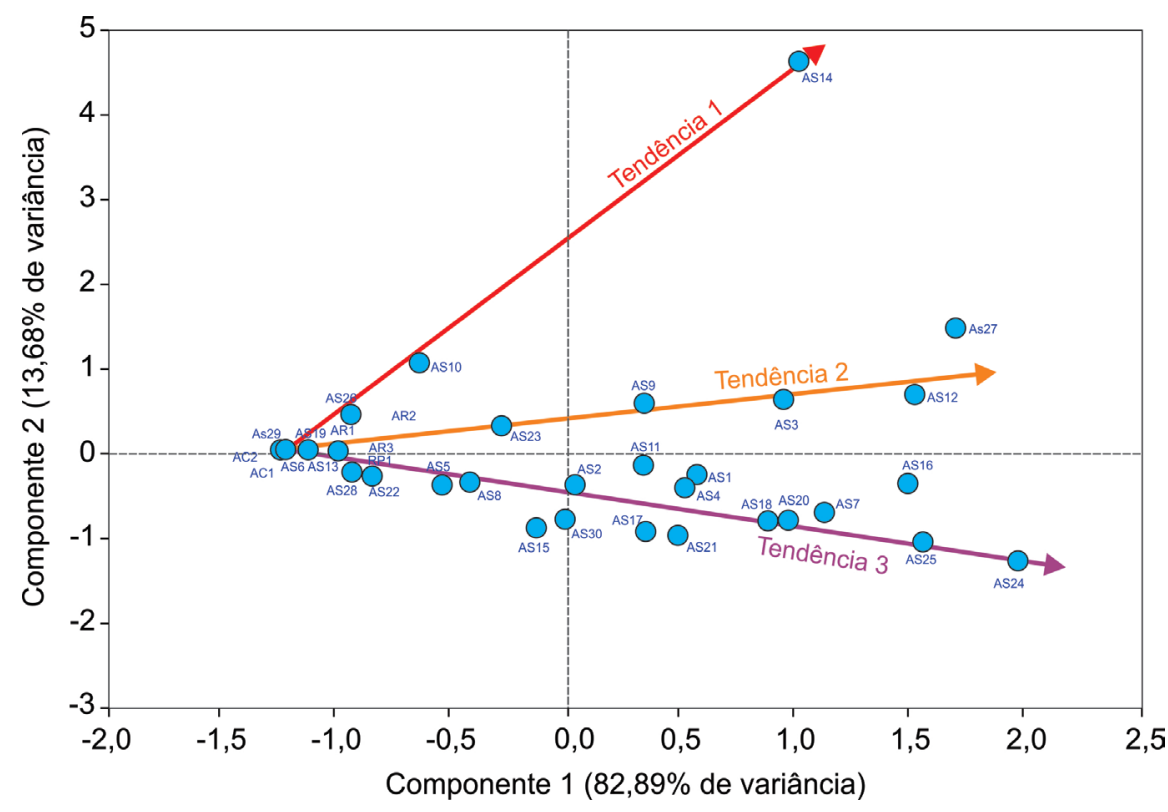

FIGURA 6 - Agrupamento por Componentes Principais, ilustrando que as amostras de água subterrânea, superficial e meteórica se distribuem ao longo de três tendências distintas. 
TABELA 3 - Matriz de correlação entre cátions e ânions maiores.
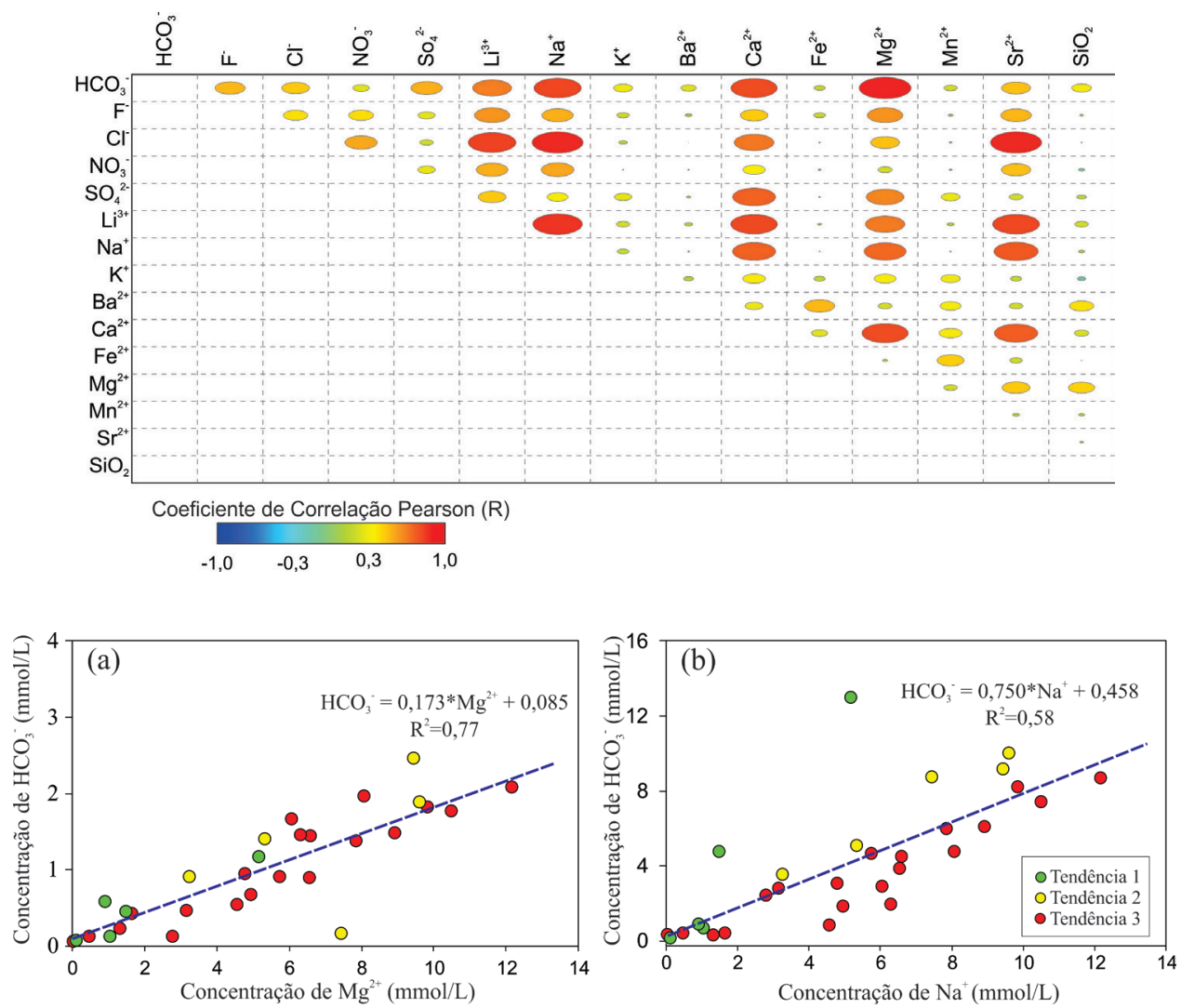

FIGURA 7 - Gráficos de dispersão entre as concentrações de $\mathrm{HCO}_{3}^{-}, \mathrm{Mg}^{2+}$ e $\mathrm{Na}^{+}$: a) Concentração de $\mathrm{Mg}^{2+}$; b) Concentração de $\mathrm{Na}^{+}$.

análise de regressão linear múltipla não produziu um acréscimo do $\mathrm{R}^{2}$ ajustado, indicando que este cátion não explica estatisticamente as variações de $\mathrm{HCO}_{3}^{-}$.

$$
\mathrm{HCO}_{3}^{-}=3,116 \mathrm{Mg}^{2+}+0,340 \mathrm{Na}^{+}+0,692 \text { (Eq. 7) }
$$

A despeito dos elevados valores de correlação entre as concentrações do $\mathrm{Na}^{+} \mathrm{e} \mathrm{Cl}^{-}$, nota-se um excesso de $\mathrm{Na}^{+}$em relação ao $\mathrm{Cl}^{-}$nas amostras das Tendências 2 e 3 (Figura 8), particularmente em concentrações de $\mathrm{Cl}^{-}$acima de $1 \mathrm{mmol}$, indicando que a dissolução do $\mathrm{NaCl}$ e a evaporação não são as únicas fonte de $\mathrm{Na}^{+}$na água. De maneira oposta, as amostras da Tendência 1 encontram-se próximas da relação $1 \mathrm{mmol}$ de $\mathrm{Na}^{+}$para cada mmol de $\mathrm{Cl}^{-}$.

Tendo em vista que o $\mathrm{Cl}^{-}$não é o único ânion associado ao $\mathrm{Na}^{+}$, foram realizadas análises de regressão múltipla que indicaram que o $\mathrm{Cl}^{-}$explica $73,8 \%$ das variações do $\mathrm{Na}^{+}$, enquanto o $\mathrm{HCO}_{3}{ }^{-}$ explica $20,1 \%$ dessas variações. $\mathrm{O}_{\mathrm{SO}_{4}{ }^{2-}}$ não apresentou acréscimos significativos do $\mathrm{R}^{2}$ ajusta- do, indicando que este ânion não é estatisticamente determinante para explicar as variações do $\mathrm{Na}^{+}$. Este resultado sugere que os incrementos de $\mathrm{Na}^{+}$ são majoritariamente associados à evaporação da

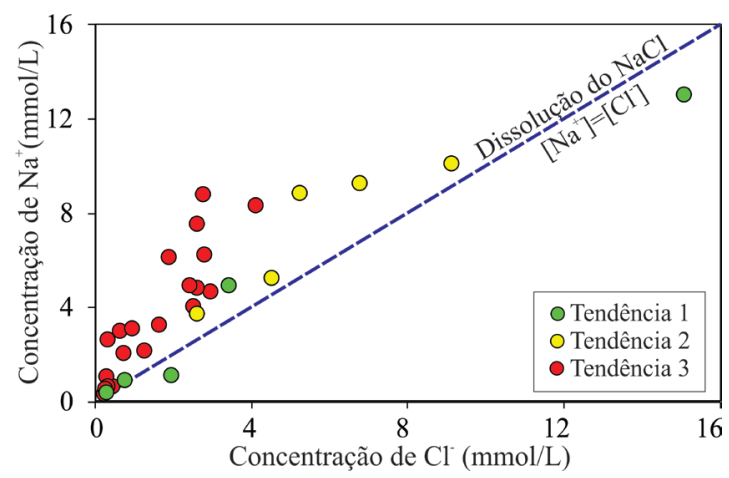

FIGURA 8 - Gráfico de dispersão entre as concentrações de $\mathrm{Cl}^{-}$e $\mathrm{Na}^{+}$. Verifica-se excesso de $\mathrm{Na}^{+}$em relação ao $\mathrm{Cl}^{-}$, indicando que a dissolução do $\mathrm{NaCl}$ não é o único processo atuante no incremento das concentrações de $\mathrm{Na}^{+}$. 
água contendo $\mathrm{NaCl}$ dissolvido, enquanto a hidrólise de silicatos contendo sódio possui um papel secundário. A equação 8 representa o modelo obtido a partir da análise de regressão linear múltipla para prever as variações de $\mathrm{Na}^{+}$em função das variações de $\mathrm{Cl}^{-}$e $\mathrm{HCO}_{3}^{-}$.

$$
\mathrm{Na}^{+}=0,714 \mathrm{Cl}^{-}+0,485 \mathrm{HCO}_{3}^{-}-0,106 \quad \text { (Eq. 8) }
$$

\subsection{Simulação geoquímica}

A amostra de água subterrânea AS06 (Tabela 1) foi utilizada como solução inicial na simulação geoquímica, tendo em vista que apresenta o menor grau de mineralização, seja esta relacionada à evapotranspiração ou à interação rocha-água. Como observado na figura 6, as amostras AS14, AS27 e AS24 representam as amostras mais mineralizadas e situadas respetivamente nos extremos das tendências 1, 2 e 3 no ACP, motivo pelo qual foram empregadas como referência para calibração das simulações geoquímicas.

$\mathrm{O}$ ajuste nas simulações indica que a evaporação necessária para alcançar as concentrações de $\mathrm{Cl}^{-}$observadas nas amostras AS14, AS27 e AS24 são, respectivamente, de 97,9\%, 96,67\% e $90,0 \%$. Para reproduzir plagioclásios com proporções distintas de cálcio e sódio em suas composições, foram utilizadas massas variáveis de anortita e albita para interação com a água. Os valores de $\mathrm{CO}_{2}$ dissolvido foram ajustados para representar diferentes condições de $\mathrm{PCO}_{2}$ nos aquíferos e produzir concentrações hidrogeniônicas e alcalinidades próximas das observadas. As fases minerais empregadas como referência basearam-se no contexto geológico das fontes, enquanto as massas de cada fase reagida foram obtidas a partir de ajustes manuais, apresentadas na tabela 4 .

TABELA 4 - Massas dos minerais reagidos com a água nas três tendências simuladas.

\begin{tabular}{lccc}
\hline $\begin{array}{l}\text { Minerais } \\
\text { reagidos }(g)\end{array}$ & $\begin{array}{c}\text { Tendência } \\
1\end{array}$ & $\begin{array}{c}\text { Tendência } \\
2\end{array}$ & $\begin{array}{c}\text { Tendência } \\
3\end{array}$ \\
\hline Anortita & 0,45 & 0,60 & 0,20 \\
Albita & 0,00 & 0,52 & 1,50 \\
Feldspato potássico & 0,015 & 0,04 & 0,03 \\
Anfibólio & 0,00 & 0,15 & 0,28 \\
\hline
\end{tabular}

As composições finais para os três conjuntos de simulações realizadas são apresentadas na tabela 5. A tabela 6 apresenta as massas de caulini- ta e quartzo produzidas a partir da supersaturação e precipitação destas fases minerais nas três trajetórias de evolução hidroquímica simuladas.

TABELA 5 - Solução inicial e soluções finais obtidas após simulação das reações água-rocha.

\begin{tabular}{|c|c|c|c|c|}
\hline Parâmetro & $\begin{array}{c}\text { Solução } \\
\text { Inicial }\end{array}$ & $\begin{array}{c}\text { Tendência } 1 \\
\text { simulado }\end{array}$ & $\begin{array}{c}\text { Tendência } 2 \\
\text { simulado }\end{array}$ & $\begin{array}{c}\text { Tendência } 3 \\
\text { simulado }\end{array}$ \\
\hline pH & 5,14 & 7,230 & 7,24 & 7,34 \\
\hline Força iônica & $3,07 \times 10^{-4}$ & 0,028279 & 0,025507 & 0,019679 \\
\hline $\mathrm{CE}(\mu \mathrm{S} / \mathrm{cm})$ & 47,08 & 2007,430 & 1712,82 & 1259,31 \\
\hline $\mathrm{Na}^{+}(\mathrm{mg} / \mathrm{L})$ & 6,45 & 352,900 & 233,30 & 193,10 \\
\hline $\mathrm{Ca}^{2+}(\mathrm{mg} / \mathrm{L})$ & 1,38 & 103,700 & 109,10 & 60,06 \\
\hline $\mathrm{K}^{+}(\mathrm{mg} / \mathrm{L})$ & 0,00 & 2,090 & 5,60 & 4,20 \\
\hline $\mathrm{Mg}^{2+}(\mathrm{mg} / \mathrm{L})$ & 1,23 & 48,400 & 50,70 & 48,81 \\
\hline $\mathrm{Cl}^{-}(\mathrm{mg} / \mathrm{L})$ & 8,61 & 528,300 & 349,50 & 112,40 \\
\hline $\mathrm{HCO}_{3}^{-}(\mathrm{mg} / \mathrm{L})$ & 4,11 & 352,900 & 605,60 & 743,20 \\
\hline $\mathrm{SO}_{4}{ }^{2-}(\mathrm{mg} / \mathrm{L})$ & 2,88 & 84,470 & 19,97 & 21,00 \\
\hline $\mathrm{NO}_{3}^{-}(\mathrm{mg} / \mathrm{L})$ & 0,21 & 9,810 & 5,89 & 2,08 \\
\hline $\mathrm{F}^{-}(\mathrm{mg} / \mathrm{L})$ & 0,12 & 1,950 & 1,87 & 0,74 \\
\hline $\mathrm{SiO}_{2}(\mathrm{aq})(\mathrm{mg} / \mathrm{L})$ & 9,13 & 5,965 & 5,97 & 5,98 \\
\hline
\end{tabular}

TABELA 6 - Massa de minerais produzidos a partir da interação água-rocha nos três cenários simulados.

\begin{tabular}{cccc}
\hline \multirow{2}{*}{ Mineral } & \multicolumn{3}{c}{ Massa de minerais produzidos $(g)$} \\
& Tendência 1 & Tendência 2 & Tendência 3 \\
\hline Quartzo & 0,0431 & 0,4968 & 0,9027 \\
Caulinita & 0,4245 & 0,7964 & 0,9379 \\
\hline
\end{tabular}

A figura 9 apresenta a comparação dos diagramas de Stiff das três soluções geradas pelas simulações geoquímicas (Tabela 4) com os membros finais de cada tendência (amostras AS14, AS27 e AS24), demonstrando a sua similaridade.

A tabela 7 apresenta a porcentagem de incremento de STD devido à evapotranspiração e à interação rocha-água, indicando forte dissimilaridade nas proporções observadas para as três tendências.

TABELA 7 - Proporção do aumento de STD associado aos processos de evapotranspiração e interação rocha-água, calculados a partir da calibração dos modelos geoquímicos.

\begin{tabular}{lccc}
\hline Processo & Tendência 1 & Tendência 2 & Tendência 3 \\
\hline Evapotranspiração & 90,13 & 61,13 & 16,26 \\
Interação rocha/água & 9,87 & 38,87 & 83,74 \\
\hline
\end{tabular}




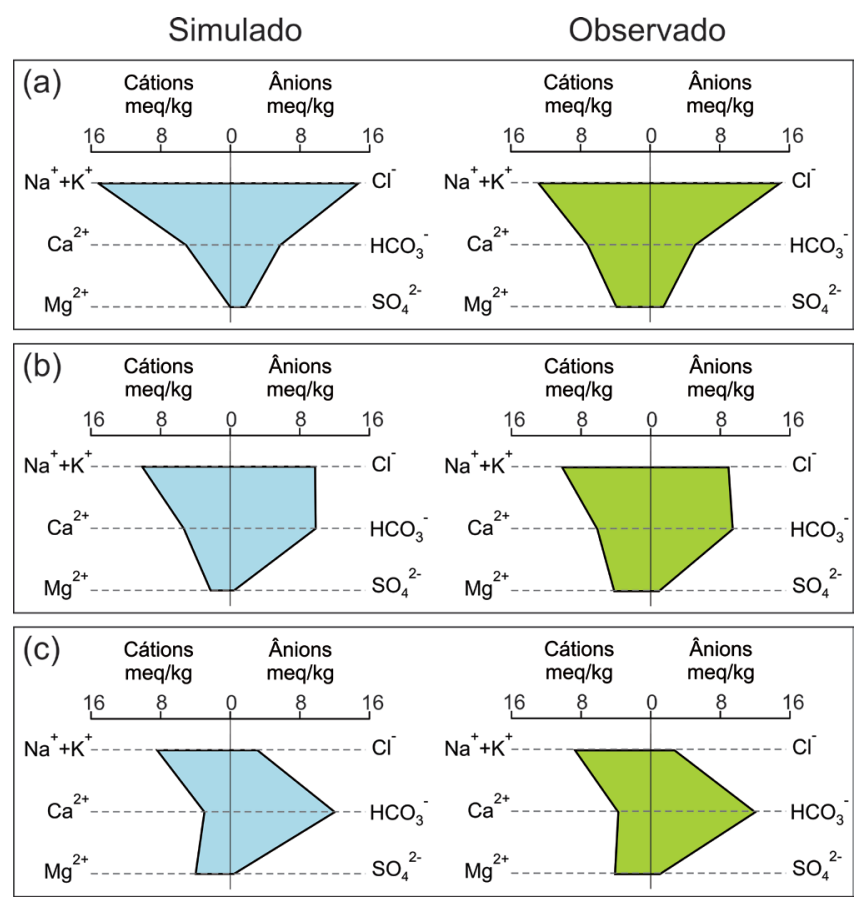

FIGURA 9 - Comparação dos diagramas de Stiff das soluções geradas pela simulação (em azul) com as soluções observadas (em verde): a) Tendência 1 com a amostra AS-14; b) Tendência 2 com a amostra AS27; c) Tendência 3, com a amostra AS24.

\section{DISCUSSÃO}

A salinidade da água é um parâmetro mensurável pela concentração de sólidos totais dissolvidos (STD). Entretanto, em muitas situações, apenas medidas de condutividade elétrica (CE) são realizadas para avaliar a salinização de águas subterrâneas (ex: MONTENEGRO et al. 2003, ANDRADE et al. 2012, SILVA et al. 2018). A proposição do modelo empírico relacionando o STD ao $\mathrm{CE}$ (Equação 6), permite que as medidas de $\mathrm{CE}$ forneçam valores equivalentes de STD, permitindo estimativas mais precisas da salinidade da água subterrânea no semiárido brasileiro.

Quando dois ou mais processos de salinização estão atuantes simultaneamente, a avaliação quantitativa da importância desses processos é bastante difícil de ser obtida. A Análise de Componentes Principais mostrou-se uma ferramenta potencialmente importante para distinção dos diferentes processos que promovem o incremento de sais dissolvidos na água. Embora possa discriminar essas diferentes tendências, a quantificação dos processos envolvidos pode ser somente alcançada a partir de simulações geoquímicas. Por esta razão, a abordagem proposta no presente trabalho, acoplando análises estatísticas e simulações geoquímicas, permite distinguir a participação de cada um dos processos na salinização.

As regressões lineares múltiplas permitiram verificar que o $\mathrm{Na}^{+}$está majoritariamente associado ao $\mathrm{Cl}^{-}$(Figura 8), indicando que a principal fonte do $\mathrm{Na}^{+}$são os aerossóis marinhos. Entretanto, é possível notar que as amostras classificadas dentro da Tendência 3 possuem um excesso de $\mathrm{Na}^{+} \mathrm{em}$ relação ao $\mathrm{Cl}^{-}$, indicando que nestas amostras existe uma outra fonte deste cátion, provavelmente associada à hidrólise de plagioclásios. De maneira dissimilar, nota-se que as amostras da Tendência 1 possuem valores de $\mathrm{Na}^{+} \mathrm{e} \mathrm{Cl}$ próximos de uma relação de 1:1, sugerindo uma fonte majoritariamente associada à dissolução do $\mathrm{NaCl}$ presente em aerossóis marinhos. Por outro lado, o $\mathrm{Mg}^{2+}$, que pode ser igualmente proveniente de aerossóis marinhos, está associado ao $\mathrm{HCO}_{3}{ }^{-}$, indicando que a interação rocha-água é provavelmente controlada pela dissolução de anfibólios.

Independentemente de sua origem, a salinização pode promover a perda de potabilidade da água em razão do incremento da concentração de espécies químicas nocivas à saúde humana. Duas das 30 amostras de água subterrânea avaliadas (Tabela 1; amostras AS-14 e AS-27) são impróprias para 
o consumo em razão das concentrações de $\mathrm{Cl}^{-}$estarem acima do limite de potabilidade para águas subterrâneas (CONAMA 396/2008), isto é, 250 $\mathrm{mg} / \mathrm{L}$. Essas amostras situam-se nos extremos das Tendências 1 e 2 (Figura 6), situação em que a evapotranspiração atuou de maneira mais intensa. Este fato reforça que em condições extremas a evapotranspiração pode comprometer a potabilidade da água. De maneira similar ao $\mathrm{Cl}^{-}$, duas amostras (AS12 e AS24) apresentaram concentrações de $\mathrm{F}^{-}$acima do limite determinado para águas subterrâneas (CONAMA 396/2008), de 1,5 mg/L. A amostra AS-12 situa-se próximo do extremo da Tendência 2, enquanto a amostra AS24, no extremo da Tendência 3, indicando que ambos os processos, evaporação e interação rocha-água, podem ser responsáveis por fortes incrementos na concentração de $\mathrm{F}^{-}$e consequente perda de potabilidade da água subterrânea na área de estudo. Os resultados das simulações geoquímicas indicam que evaporações de $97,9 \%$ e $96,67 \%$, utilizadas para reproduzir, respectivamente, as Tendências 1 e 2, são suficientemente elevadas para incrementar as concentrações de $\mathrm{F}^{-}$acima do limite de potabilidade. A presença de concentrações elevadas de $\mathrm{F}^{-}$na amostra AS24, na qual a interação rocha-água foi mais intensa, bem como sua ausência nos resultados da simulação geoquímica, indicam que parte do $\mathrm{F}^{-}$pode ter sido liberado a partir da dissolução de minerais como fluorita, biotita ou turmalina, minerais que possuem este elemento em sua composição. Este fato indica que as condições climáticas e geoquímicas na área de estudo podem incrementar as concentrações de $\mathrm{Cl}^{-}$e o F , superando os limites de potabilidade, exigindo atenção.

Destaca-se que as simulações realizadas são sensíveis à solução inicial empregada. Todas partiram da premissa que a amostra AS06 é a amostra mais representativa das condições iniciais, na qual a água meteórica interage com aerossóis marinhos, uma vez que soluções menos mineralizadas exigiriam maiores taxas de evaporação. As pequenas diferenças entre a solução da Tendência 1 e a amostra AS14, ilustradas na figura 9a, são decorrentes da diferença de tipologia hidroquímica entre as amostras AS06 e AS14, impedindo que a evaporação da primeira produza uma solução similar à segunda. Outro ponto a ser destacado é que a interação rocha-água e a posterior evaporação da solução resultante poderia gerar resultados similares aos apresentados no presente trabalho. Entretanto, assume-se que este cenário é pouco provável, tendo em vista que a evapotranspiração ocorre em por- ções subsuperficiais rasas, enquanto a interação rocha-água deve ocorrer em porções profundas, onde a circulação da água é ineficiente e o tempo de residência elevado, permitindo que a água possa interagir significativamente com a rocha.

A despeito do presente trabalho empregar a premissa de que a salinização é mediada por processos naturais, é provável que a ação antrópica desempenhe um importante papel na salinização. Para exemplificar, CARDOSO et al. (2020) verificaram que as represas construídas para armazenamento de água ocupam parcela significativa da bacia do rio Cachoeira e podem influenciar nas taxas de evapotranspiração, bem como acumular parte da água que iria chegar aos rios na forma de escoamento superficial e fluxo de base.

Embora neste trabalho tenham sido enfatizados os processos geoquímicos que controlam a qualidade da água subterrânea, as constatações aqui apresentadas têm implicações importantes para a dinâmica da circulação e armazenamento de água em subsuperfície. As três tendências geoquímicas observadas na Análise de Componentes Principais podem estar associadas a três tipos distintos de armazenamento de água em subsuperfície. As amostras das Tendências 2 e 3 provavelmente refletem águas armazenadas em descontinuidades profundas, onde a circulação da água é menos efetiva, propiciando elevados tempos de residência e, consequentemente, forte interação entre a água e a rocha. As amostras da Tendência 1, por outro lado, são menos comuns e representam águas em que as concentrações de sais são majoritariamente resultado de forte evapotranspiração. Uma possível explicação para existência dessas águas é seu armazenamento no manto de intemperismo pouco espesso em porções rasas, assentadas sobre rochas sãs com permeabilidade reduzida, situação em que a água ascende por capilaridade na zona não-saturada durante os períodos de estiagem, propiciando a precipitação de sais nesta zona. Durante os períodos chuvosos, a água meteórica que infiltra no solo dissolve esses sais, transportando os íons dissolvidos até a zona saturada. Os ciclos de precipitação e solubilização dos sais vão, assim, incrementando progressivamente a salinidade da água.

\section{CONCLUSÕES}

A abordagem proposta no presente trabalho permitiu a distinção dos processos envolvidos na salinização de aquíferos no semiárido. A técnica 
estatística da Análise de Componentes Principais, complementada pelas simulações geoquímicas, identificou diferentes tendências, nas quais foi possível verificar a importância relativa dos processos de evapotranspiração e da interação rocha-água.

Os resultados da simulação revelam que as porcentagens de evapotranspiração no incremento de concentrações de sais totais dissolvidos nas amostras correspondentes às Tendências 1,2 e 3, são, respectivamente, de $90,13 \%, 61,13 \%$ e $16,26 \%$, enquanto as parcelas restantes estão associadas à interação rocha-água.

Duas amostras apresentaram concentrações de $\mathrm{Cl}^{-}$acima da potabilidade em razão da evapotranspiração, enquanto outras duas apresentaram concentrações de $\mathrm{F}^{-}$acima da potabilidade, devido à evapotranspiração e à interação rocha-água, indicando que os processos de salinização podem comprometer a potabilidade da água subterrânea local.

\section{AGRADECIMENTOS}

Os autores são gratos pela FUNDUNESP pela concessão de bolsas de pesquisa e aos revisores e à equipe editorial da revista, cujas observações permitiram o aprimoramento do presente trabalho.

\section{REFERÊNCIAS BIBLIOGRÁFICAS}

ADIMALLA, N.; LI, P. 2019. Occurrence, health risks, and geochemical mechanisms of fluoride and nitrate in groundwater of the rock-dominant semi-arid region, Telangana State, India. Human and Ecological Risk Assessment: An International Journal, 25(12): 81-103. https://doi.org/10.1080/1080703 9.2018 .1480353

ALMEIDA， J.R.F.; FRISCHKORN， H. 2015. Salinization mechanisms of a small alluvial aquifer in the semiarid region of northeast Brazil. Revista Brasileira de Engenharia Agrícola e Ambiental, 19(7): 643-649. https://doi.org/10.1590/1807-1929/agriambi. v19n7p643-649

ANDRADE， L.G.D.A.S.; GHEVI, H.R.; MEDEIROS, J.F. 1999. Composição química de águas do cristalino do Nordeste brasileiro. Revista Brasileira de Engenharia Agrícola e Ambiental, 3(1), 11-17.
ANDRADE, T.S.; MONTENEGRO, S.M.; MONTENEGRO, A.A.; RODRIGUES, D.F. 2012. Variabilidade espaço-temporal da condutividade elétrica da água subterrânea na região semiárida de Pernambuco. Revista Brasileira de Engenharia Agrícola e Ambiental, 16(5): 496-504. http://dx.doi. org/10.1590/S1415-43662012000500005

ARAÚJO, T.G.; SOUZA, M.F.; MELLO, W.Z.D.; SILVA, D.M. 2015. Bulk atmospheric deposition of major ions and dissolved organic nitrogen in the lower course of a tropical river basin, southern Bahia, Brazil. Journal of the Brazilian Chemical Society, 26(8): 1692-1701. https://doi. org/10.5935/0103-5053.20150143

BANKS, D.; FRENGSTAD, B. 2006. Evolution of groundwater chemical composition by plagioclase hydrolysis in Norwegian anorthosites. Geochimica et Cosmochimica Acta, 70(6): 1337-1355. https://doi. org/10.1016/j.gca.2005.11.025

BARBOSA, J.S.; SABATÉ, P. 2002. Geological features and the Paleoproterozoic collision of four Archean crustal segments of the São Francisco Craton, Bahia, Brazil: a synthesis. Anais da Academia Brasileira de Ciências, 74(2): 343-359. http://dx.doi.org/10.1590/ S0001-37652002000200009

BETHKE, C.; YEAKEL, S. 2014. The Geochemist's Workbench ${ }^{\circledR}$ Release 10 - GWB Essentials Guide. https://www.gwb.com/pdf/GWB10/ GWBessentials.pdf

BOUAZIZ, M.; MATSCHULLAT, J.; GLOAGUEN, R. 2011. Improved remote sensing detection of soil salinity from a semiarid climate in Northeast Brazil. Comptes Rendus Geoscience, 343(11-12): 795-803. https://doi.org/10.1016/j.crte.2011.09.003

BOUZOURRA, H.; BOUHLILA, R.; ELANGO, L.; SLAMA, F.; OUSLATI, N. 2015. Characterization of mechanisms and processes of groundwater salinization in irrigated coastal area using statistics, GIS, and hydrogeochemical investigations. Environmental Science and Pollution Research, 22(4): 2643-2660. https://doi. org/10.1007/s11356-014-3428-0 
CARDOSO, S.B.; DA CUNHA, C.F.; ENGELBRECHT, B.Z.; CHANG, H.K. 2020 Detecção e delimitação de pequenos reservatórios na Bacia Hidrográfica do Rio Cachoeira, Bahia, utilizando imagens multiespectrais. Holos Environment, 20(4): 458-475. https://doi.org/10.14295/holos. v20i4. 12391

ELANGO, L.; KANNAN, R. 2007. Rock-water interaction and its control on chemical composition of groundwater. Developments in Environmental Science, (5): 229-243. https:// doi.org/10.1016/S1474-8177(07)05011-5

ENGELBRECHT, B.Z.; GONÇALVES， R.D.; TERAMOTO, E.H.; CHANG, H.K. 2019. Disponibilidade hídrica e balanço hídrico da Bacia do Rio Cachoeira na Região de Itabuna/BA. Geociências, 38(3): 731-740.

HAMMER, Ø.; HARPER, D.A.T.; RYAN, P.D. 2009. PAST 3.0: Paleontological statistics software package for education and data analysis.Palaeontologia electronica, 4(1): 9.

HARA, K.; OSADA, K.; KIDO, M.; HAYASHI, M.; MATSUNAGA, K.; IWASAKA, Y.; FUKATSU, T. 2004. Chemistry of seasalt particles and inorganic halogen species in Antarctic regions: Compositional differences between coastal and inland stations. Journal of Geophysical Research: Atmospheres, 109: D20208. https://doi. org/10.1029/2004JD004713

HUMPHRIES, M.S.; KINDNESS, A.; ELLERY, W.N.; HUGHES, J.C. 2011. Water chemistry and effect of evapotranspiration on chemical sedimentation on the Mkuze River floodplain, South Africa. Journal of Arid Environments, 75(6): 555-565. https://doi.org/10.1016/j. jaridenv.2011.01.013

INSA - INSTITUTO NACIONAL DO SEMIÁRIDO. 2020. Mapa do Semiárido. Disponível em www.insa.gov.br/sigsab. Acessado em 17 jul. 2020.

KARROUM, M.; ELGETTAFI, M.; ELMANDOUR, A.; WILSKE, C.; HIMI, M.; CASAS, A. 2017. Geochemical processes controlling groundwater quality under semiarid environment: a case study in central Morocco. Science of the Total Environment,
609: 1140-1151. https://doi.org/10.1016/j. scitotenv.2017.07.199

KIM, Y.; LEE, K.S.; KOH, D.C.; LEE, D.H.; LEE, S.G.; PARK, W.B.; WOO, N.C. 2003. Hydrogeochemical and isotopic evidence of groundwater salinization in a coastal aquifer: a case study in Jeju volcanic island, Korea. Journal of Hydrology, 270(3-4): 282-294. https://doi.org/10.1016/ S0022-1694(02)00307-4

LI, J.; WANG, Y.; XIE, X. 2016. Cl/Br ratios and chlorine isotope evidences for groundwater salinization and its impact on groundwater arsenic, fluoride and iodine enrichment in the Datong basin, China. Science of the Total Environment, 544: 158-167. https://doi. org/10.1016/j.scitotenv.2015.08.144

LOURENÇO, C.; RIBEIRO, L.; CRUZ, J. 2010. Classification of natural mineral and spring bottled waters of Portugal using Principal Component Analysis. Journal of Geochemical Exploration, 107(3): 362-372. https://doi.org/10.1016/j.gexplo.2010.08.001

LUCIO, M.Z.T.P.D.Q.L.; SANTOS, S.S.D.; SILVS, D.M.L.D. 2012. Hydrochemistry of Cachoeira River (Bahia State, Brazil). Acta Limnologica Brasiliensia, 24(2): 181-192. https://doi. org/10.1590/S2179-975X2012005000037

MANCA, F.; CAPELLI, G.; TUCCIMEI, P. 2015. Sea salt aerosol groundwater salinization in the Litorale Romano Natural Reserve (Rome, Central Italy). Environmental Earth Sciences, 73(8): 4179-4190. https://doi.org/10.1007/ s12665-014-3704-9

MCDOWELL, W.H.; SÁNCHEZ, C.G.; ASBURY, C.E.; PÉREZ, C.R.R. 1990. Influence of sea salt aerosols and long range transport on precipitation chemistry at El Verde, Puerto Rico. Atmospheric Environment. Part A. General Topics, 24(11): 2813-2821. https:// doi.org/10.1016/0960-1686(90)90168-M

MONTENEGRO, S.M.G.L.; MONTENEGRO, A.D.A.; MACKAY, R.; OLIVEIRA, A.D. 2003. Dinâmica hidro-salina em aquífero aluvial utilizado para agricultura irrigada familiar em região semiárida. Revista Brasileira de Recursos Hídricos, 8(2): 85-92. 
MOREIRA-NORDEMANN, L.M. 1984. Salinity and weathering rate of rocks in a semi-arid region. Journal of Hydrology, 71(1-2): 131-147. https://doi. org/10.1016/0022-1694(84)90074-X

NAGARAJU, A.; THEJASWI, A.; SUN, L. 2016. Statistical analysis of high fluoride groundwater hydrochemistry in Southern India: Quality assessment and implications for source of fluoride. Environmental Engineering Science, 33(7): 471-477. https:// doi.org/10.1089/ees.2015.0511

NOGUEIRA, G.; STIGTER, T.Y.; ZHOU, Y.; MUSSA, F.; JUIZO, D. 2019. Understanding groundwater salinization mechanisms to secure freshwater resources in the waterscarce city of Maputo, Mozambique. Science of The Total Environment, 661: 723-736. https://doi.org/10.1016/j.scitotenv.2018.12.343

PAUWELS, H.; NÉGREL, P.; DEWANDEL, B.; PERRIN, J.; MASCRÉ, C.; ROY, S.; AHMED, S. 2015. Hydrochemical borehole logs characterizing fluoride contamination in a crystalline aquifer (Maheshwaram, India). Journal of Hydrology, 525: 302-312. https:// doi.org/10.1016/j.jhydrol.2015.03.017

PINHO, I.C.A. 2005. Geologia dos Metatonalitos/ Metatrondhjemitos e Granulitos básicos associados das regiões de CamamuUbaitaba-Itabuna. Instituto de Geociências, Universidade Federal da Bahia, Salvador, Tese de Doutorado, $164 \mathrm{p}$.

PINHO, I.C.A.; BARBOSA, J.S.F.; MENEZES LEAL, A.B.; MARTIN, H.; PEUCAT, J.J. 2011. Geochemical modelling of the tonalitic and trondhjemitic granulites from the Itabuna-Salvador-Curaçá Block, Bahia, Brazil. Journal of South American Earth Sciences, 31(2): 312-323. https://doi. org/10.1016/j.jsames.2010.11.004

RE, V.; SACCHI, E. 2017. Tackling the salinitypollution nexus in coastal aquifers from arid regions using nitrate and boron isotopes. Environmental Science and Pollution Research, 24(15): 13247-13261. https://doi. org/10.1007/s11356-017-8384-z

SALAMA, R.B.; OTTO, C.J.; FITZPATRICK, R.W. 1999. Contributions of groundwater conditions to soil and water salinization. Hydrogeology Journal, 7(1): 46-64. https:// doi.org/10.1007/s100400050179

SANTOS, J.W.; PAULA, F.C.F.; REGO, N.A. 2008. Tipologia fluvial da Bacia Hidrográfica do Rio Salgado - Sul da Bahia. Revista Brasileira de Recursos Hídricos, 13: 217-226.

SILVA, P.S.; CAMPOS, J.E.G.; CUNHA, L.S.; MANCINI, L.H. 2018. Relationships of stable isotopes, water-rock interaction and salinization in fractured aquifers, Petrolina region, Pernambuco State, Brazil. REM - International Engineering Journal, 7l(1): 19-25. http://dx.doi. org/10.1590/0370-44672016710178

SUDENE - SUPERINTENDÊNCIA DO DESENVOLVIMENTO DO NORDESTE. 2017. Delimitação do Semiárido. Disponível em http://www.sudene.gov.br/delimitacaodo-semiarido. Acessado em 17 jul. 2020.

TABACHNICK, B.G.; FIDELL, L.S.; ULLMAN, J.B. 2007. Using multivariate statistics. Pearson, Boston, MA, 983 p.

TERAMOTO, E.H.; ENGELBRECHT, B.Z.; GONÇALVES, R.D.; CHANG, H.K. 2018. Caracterização hidroquímica e isotópica dos aquíferos fissurais da região de Itabuna/BA. Águas Subterrâneas, 32(2): 228-236. https:// doi.org/10.14295/ras.v32i2.29151

TERAMOTO, E.H.; GONÇALVES, R.D.; STRADIOTO, M.R.; ENGELBRECHT; B.Z.; CHANG, H.K. 2019a. Modelagem da interação Água/Rocha nos aquíferos fraturados da região de Itabuna/BA. Anuário do Instituto de Geociências, 42(1): 735-741. http://dx.doi.org/10.11137/2019_1_735_741

TERAMOTO, E.H.; NAVARRO, J.; KIANG, C.H. 2019b. Avaliação geoquímica das águas envasadas de aquíferos cristalinos no sul e sudeste do Brasil. Revista do Instituto Geológico, 40(2): 53-67. https://doi. org/10.33958/revig.v40i2.647

THYNE, G.; GÜlER, C.; POETER, E. 2004. Sequential analysis of hydrochemical data for watershed characterization. 
Groundwater, 42(5): 711-723. https://doi. org/10.1111/j.1745-6584.2004.tb02725.x

TIZRO, A.T.; VOUDOURIS, K.S. 2008. Groundwater quality in the semiarid region of the Chahardouly basin, West Iran. Hydrological Processes: An International Journal, 22(16): 3066-3078. https://doi. org/10.1002/hyp.6893

TWEED, S.; LEBLANC, M.; CARTWRIGHT, I.; FAVREAU, G.; LEDUC, C. 2011. Arid zone groundwater recharge and salinisation processes; an example from the Lake Eyre Basin, Australia. Journal of Hydrology, 408(3-4): 257-275. https://doi.org/10.1016/j. jhydrol.2011.08.008

UMARANI, P.; RAMU, A.; KUMAR, V. 2019. Hydrochemical and statistical evaluation of groundwater quality in coastal aquifers in Tamil Nadu, India. Environmental
Earth Sciences, 78(15): 452. https://doi. org/10.1007/s12665-019-8414-X

WALTER, J.; CHESNAUX, R.; CLOUTIER, V.; GABOURY, D. 2017. The influence of water/ rock-water/clay interactions and mixing in the salinization processes of groundwater. Journal of Hydrology: Regional Studies, 13: 168-188. https://doi.org/10.1016/j. ejrh.2017.07.004

YOUSIF, M.; EL-AASSAR, A.H.M. 2018. Rock-water interaction processes based on geochemical modeling and remote sensing applications in hyper-arid environment: cases from the southeastern region of Egypt. Bulletin of the National Research Centre, 42(1): 4. https://doi.org/10.1186/ s42269-018-0004-7

\section{Endereço dos autores:}

Elias Hideo Teramoto - Laboratório de Estudos de Bacias - UNESP e Centro de Estudos Ambientais UNESP, Campus de Rio Claro, Av. 24-A, 1515, Bairro Bela Vista, CEP 13506-900, Rio Claro, SP, Brasil. E-mail: elias.hideo-teramoto@unesp.br

Chang Hung Kiang - Laboratório de Estudos de Bacias - UNESP, Centro de Estudos Ambientais - UNESP e Departamento de Geologia Aplicada, Instituto de Geociências e Ciências Exatas - UNESP, Campus de Rio Claro, Av. 24A, 1515, Bairro Bela Vista, CEP: 13506-900, Rio Claro, SP, Brasil. E-mail: chang@ rc.unesp.br

Artigo recebido em 21 de maio de 2020, aceito em 4 de agosto de 2020. 